\title{
Concordance of National Cancer Registration with self-reported breast, bowel and lung cancer in England and Wales: a prospective cohort study within the UK Collaborative Trial of Ovarian Cancer Screening
}

\author{
A Gentry-Maharaj ${ }^{1}$, E-O Fourkala ${ }^{1}$, M Burnell ${ }^{1}$, A Ryan ${ }^{1}$, S Apostolidou ${ }^{1}$, M Habib ${ }^{1}$, A Sharma ${ }^{1}$, M Parmar ${ }^{2}$, \\ I Jacobs ${ }^{1,3}$ and U Menon ${ }^{*, 1}$ \\ ${ }^{1}$ Gynaecological Cancer Research Centre, Women's Cancer, Institute for Women's Health, University College London, London, \\ UK; ${ }^{2}$ MRC Clinical Trials Unit, University College London, London, UK and ${ }^{3}$ Faculty of Medical and Human Sciences, University of \\ Manchester, Manchester, UK
}

Background: It has been suggested that lower UK cancer survival may be due to incomplete case ascertainment by cancer registries.

Methods: We assessed concordance between self-reported breast, bowel and lung cancer and cancer registration (CR) for 1995-2007 in England and Wales in the UK Collaborative Trial of Ovarian Cancer Screening.

Results: Concordance of breast cancer CR was higher (94.7\%:95\% Cl: 94.1-95.3\%) than for bowel (85.1\%:95\% Cl: 82.1-87.8\%) and lung (85.4\%:95\% Cl: 76.3-92.0\%). CR concordance was lower in breast cancer (94.5\% vs $98.8 \%$ ) survivors compared with deceased but the difference was small. No difference was found for bowel (85.3\% vs $94.6 \%)$ or lung (87.1\% vs $90.5 \%)$ cancer.

Conclusion: Concordance of CR and self-reported cancer is high. Incomplete registration is unlikely to be a major cause of lower UK survival rates.

International comparisons of cancer incidence and mortality are dependent on completeness of cancer registration (CR). Recently, lower survival rates have been reported for those diagnosed with primary bowel, lung, breast and ovarian cancer in the UK (1995-2007) compared with countries with similar national cancer plans (Coleman et al, 2011). Concern was raised that incomplete case ascertainment by cancer registries particularly of survivors may have contributed to this finding (Robinson et al, 2007). We report using independent case ascertainment (Parkin et al, 1994; selfreporting in the course of a clinical trial) on concordance between CR in England and Wales for 1995-2007 and self-reported breast, bowel or lung cancer in women participating in the UK Collaborative Trial of Ovarian Cancer Screening (UKCTOCS).

\section{MATERIALS AND METHODS}

This prospective study was nested within the UKCTOCS cohort of 189063 women, aged 50-74 years recruited from England and Wales (Menon et al, 2008, 2009). Women recruited from Northern Ireland were excluded. At recruitment, women reported on breast, bowel, lung or other cancer diagnosed before enrollment and date 
of diagnosis (Menon et al, 2008). At postal follow-up 3-5 years later, women were asked about ovarian, breast, bowel, lung or other cancers diagnosed after joining UKCTOCS, year of diagnosis and where treatment took place. All women provided written consent.

Women were 'flagged' through Health and Social Care Information Centre (HSCIC). All deaths and cancer diagnoses were notified using the International Classification of Disease Codes (ICD-9 and ICD-10). No data were provided on whether CR was death certificate-initiated or death certificate-only. Up-to-date CR was received on 11 October 2012.

Women self-reporting a single breast, bowel or lung cancer diagnosis at recruitment or follow-up with diagnosis dates between 1 January 1995 and 31 December 2007 were included. CR was defined as concordant if the woman had a relevant CR irrespective of number/year of CRs. Sensitivity analysis included women who self-reported more than one of the above cancers. Subgroup analysis was undertaken by regional cancer registry with Gateshead/Middlesborough assigned to Northern and Yorkshire, Liverpool/Manchester to North Western, Nottingham/Derby to Trent, Portsmouth/Bristol to South West, Royal Free/Barts to Thames, Cardiff/North Wales to Wales Cancer Registries.

Timely reporting of death is a legal requirement in the UK and the mention of cancer on the death certificate triggers collation of additional medical information. We therefore assessed concordance of CR in survivors $v s$ deceased women with the relevant cancer as primary or contributory cause of death. Women who had died with no mention of the relevant cancer on the death certificate were excluded from this analysis. In those residing in England who self-reported relevant cancer but had missing CR, in-patient and out-patient Hospital Episodes Statistics (HES) records for 2001-2010 were searched for relevant ICD codes to explore whether inclusion would improve CR concordance.

\section{RESULTS}

Of 189055 (99.9\%) who gave consent for follow-up, 10390(5.5\%) self-reported breast, bowel or lung cancer. In all, 1313 were excluded as they had not reported a diagnosis date (463) or had reported diagnosis after 2007 (256), two separate diagnosis dates (229) and multiple primary cancers (365). Of the remaining 9067 women, 5917 ( 5210 breast, 618 bowel and 89 lung) self-reported cancer diagnosis between 1995 and 2007 (Table 1).

For breast cancer, the concordance of CR was $94.7 \%$ (95\% CI: 94.1-95.3\%) with $11.1 \%$ (95\% CI: $10.3-12.0 \%$ ) of women having a ductal carcinoma in situ only registration (Table 1A). For bowel (including four carcinoma in situ) and lung cancer, the concordance of CR was $85.1 \%$ (95\%CI: $82.1-87.8 \%$ ) and $85.4 \%$ (95\% CI: 76.3-92.0\%), respectively. The difference in concordance

Table 1. (A) Number of women from England and Wales reporting breast, bowel or lung cancer diagnosis between 1995 and 2007 who had relevant cancer; $(B)$ in women who self-reported more than one of these cancers

\begin{tabular}{|c|c|c|c|}
\hline ICD-9 and ICD-10 codes & No. of women with CR & $\%$ Concordance & $95 \% \mathrm{Cl}$ \\
\hline \multicolumn{4}{|l|}{ Self-reported cancer history } \\
\hline \multicolumn{4}{|l|}{ Breast cancer $(n=5210)^{a}$} \\
\hline C50/174 CR & 4358 & 83.6 & $82.6-84.6 \%$ \\
\hline $\mathrm{D} 05 / 233 \mathrm{CR}$ & 578 & 11.1 & $10.3-12.0 \%$ \\
\hline Total (invasive $\mathrm{Br} \mathrm{Ca}+$ in situ carcinoma) & 4936 & 94.7 & $94.1-95.3 \%$ \\
\hline \multicolumn{4}{|l|}{ Bowel cancer $(n=618)$} \\
\hline C18/C19/C20/C21/C17/153/154 CR (includes D01 in situ carcinoma) & 526 & 85.1 & $82.1-87.8 \%$ \\
\hline \multicolumn{4}{|l|}{ Lung cancer $(n=89)$} \\
\hline C33/C34/162 CR & 76 & 85.4 & $76.3-92.0 \%$ \\
\hline \multicolumn{4}{|l|}{ (B) } \\
\hline ICD-9 and ICD-10 codes & No. of women with CR & $\%$ Agreement & $95 \% \mathrm{Cl}$ \\
\hline \multicolumn{4}{|l|}{ Breast cancer $(n=5274)^{a}$} \\
\hline $\begin{array}{l}\text { C50/174 CR } \\
\text { D05/233 CR }\end{array}$ & $\begin{array}{c}4389 \\
582\end{array}$ & $\begin{array}{l}84.2 \\
11.2\end{array}$ & $\begin{array}{l}82.6-84.6 \% \\
10.3-12.0 \%\end{array}$ \\
\hline Total (invasive $\mathrm{Br} \mathrm{Ca}+$ in situ carcinoma) & 4971 & 94.3 & $94.1-95.3 \%$ \\
\hline \multicolumn{4}{|l|}{ Bowel cancer $(n=669)$} \\
\hline C18/C19/C20/C21/C17/153/154 CR (includes D01 in situ carcinoma) & 559 & 83.6 & $81.7-87.5 \%$ \\
\hline \multicolumn{4}{|l|}{ Lung cancer $(n=125)$} \\
\hline C33/C34/162 CR & 81 & 64.8 & $76.3-92.0 \%$ \\
\hline \multicolumn{4}{|c|}{ 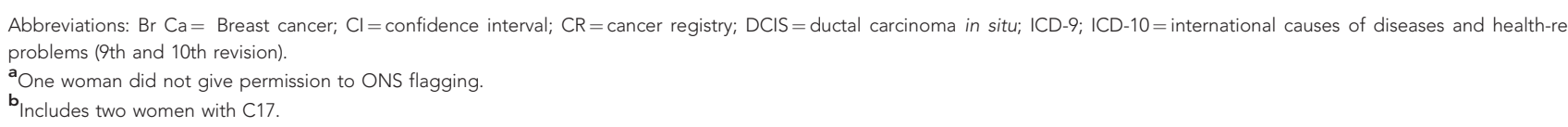 } \\
\hline
\end{tabular}




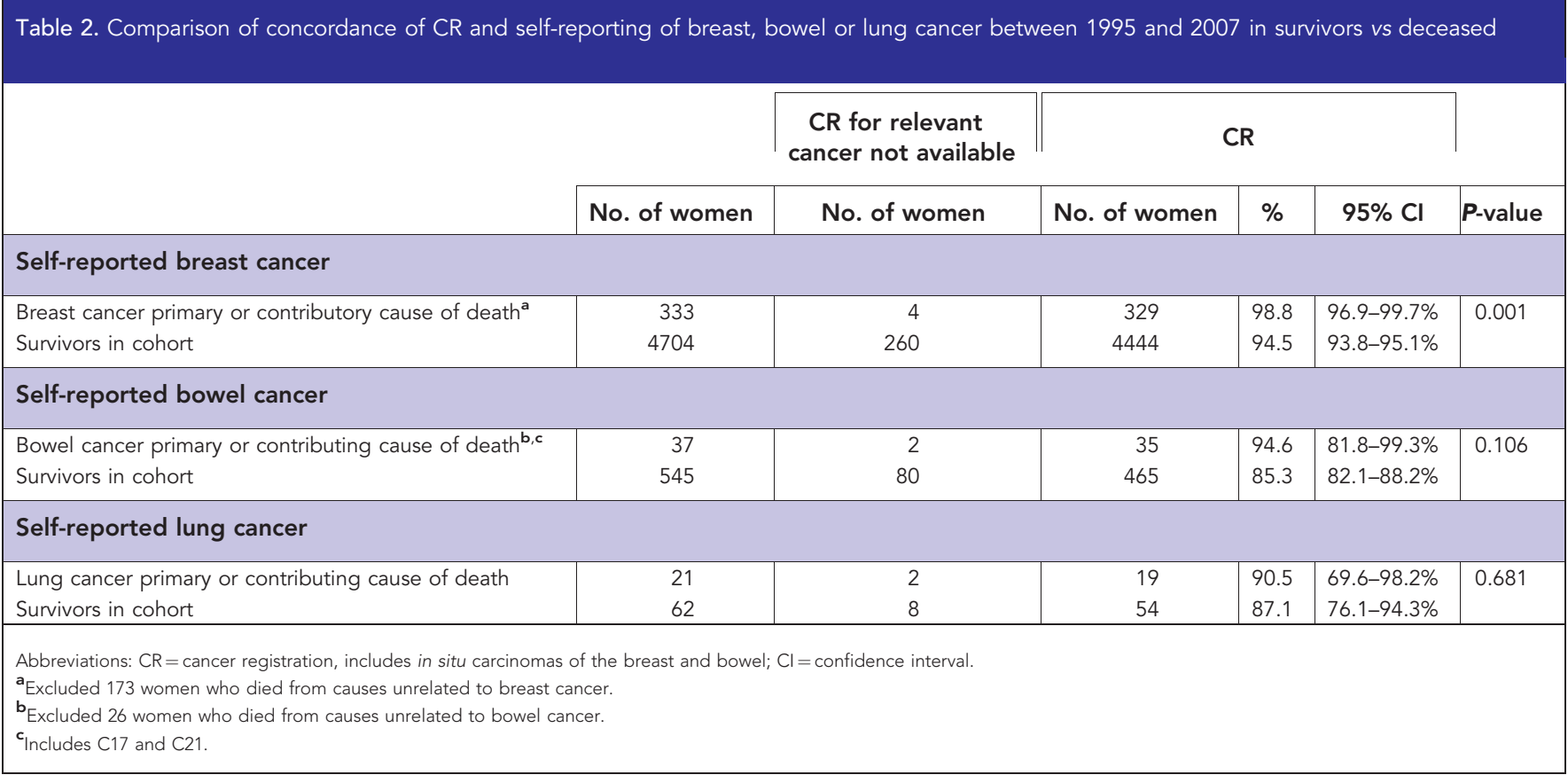

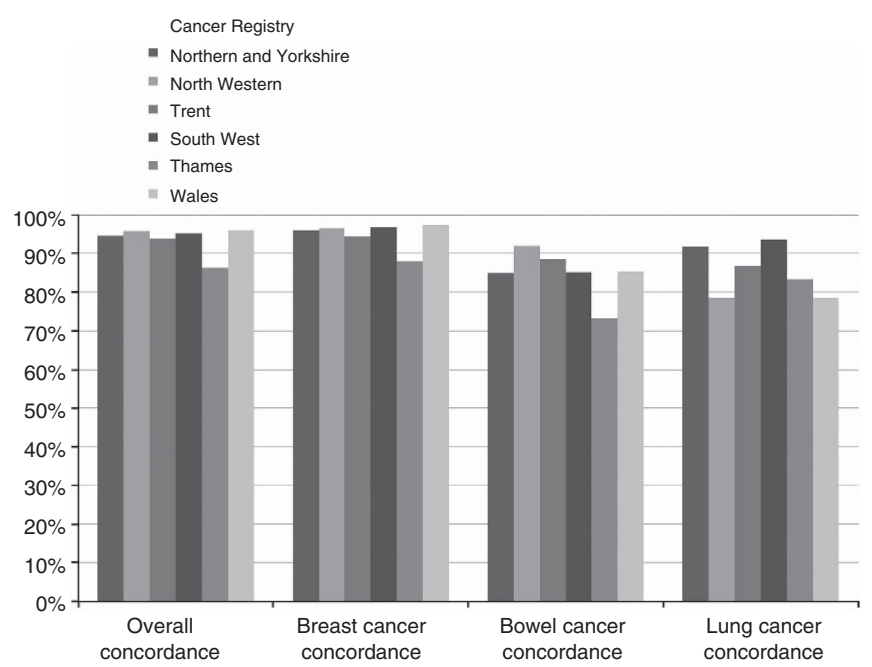

Figure 1. Concordance of self-reporting and CR for relevant cancers diagnosed between 1995 and 2007 in England and Wales by regional Cancer Registry.

of $\mathrm{CR}$ between breast, bowel and lung cancer was significant $(P<0.0001)$. Concordance improved with increasing year of diagnosis for self-reported breast cancers but not for bowel or lung cancer (data not shown). Sensitivity analysis including the 75 women who self-reported multiple of these cancers demonstrated similar concordance for breast (94.3\%) and bowel (83.6\%) but lower (64.8\%) for lung (Table 1B). Age of diagnosis (self-reported) differed in those with CR (mean 58.5, s.d. 6.8) compared with those without (mean 57.3, s.d. 7.2; $P=0.001$ ). Agreement between self-reported year of diagnosis and first relevant CR diagnosis date (defined as \pm 1 year) was $95.0 \%$ (5260 out of 5538) and was similar across the cancers.

CR concordance was lower in breast cancer $(94.5 \%$ vs $98.8 \%$, $P=0.001)$ survivors compared with deceased but the difference was small. No difference was found for bowel (85.3\% vs $94.6 \%$, $P=0.106)$ or lung $(87.1 \%$ vs $90.5 \%, P=0.681)$ cancer (Table 2$)$.

Concordance for all three cancers combined by Cancer Registry ranged from $96.0 \%$ (Wales) to $86.4 \%$ (Thames), (Figure 1). In those diagnosed between 2001 and 2007 with missing CR, HES records contained additional information on 31 (1.3\%) women with breast, $9(2.7 \%)$ with bowel and $3(5.2 \%)$ with lung cancer. These records have the potential to contribute to cancer registry data in the future. Inclusion increased concordance of CR to $96.7 \%$ for breast, $90.1 \%$ for bowel and $89.7 \%$ for lung cancer (data not shown).

\section{DISCUSSION}

Our study of 6000 women nested in a cohort of 190000 shows 95\% concordance of national CR for self-reported breast cancer in England and Wales between 1995 and 2007, 85\% for bowel and $85 \%$ for lung cancers. This compares well with reports (91-99\%) from other population-based registries (Jensen et al, 2002, Lang et al, 2003, Gathani et al, 2005). The concordance of CR was significantly lower in breast cancer survivors compared with women with a death certificate where it was a primary or contributing cause of death but the difference was only $5 \%$. Modelling suggests that disparity between concordance of CR for deceased patients and survivors needs to be around $40 \%$ to account for half of the survival differences between UK and other countries (Woods et al, 2011). Our data refute the suggestions (Beral and Peto, 2010) that the lower UK breast cancer survival is influenced mainly by lower CR in survivors. Recent reports suggests that more likely contributors to lower UK cancer survival are low cancer awareness, increased perceived barriers to symptomatic presentation, concern about wasting the doctor's time (Forbes et al, 2013), suboptimal treatment of advanced ovarian (Maringe et al, 2012) and bowel cancer (Dejardin et al, 2013).

Highest concordance of CR for self-reported breast followed by bowel and lung cancer was in keeping with previous findings (Parikh-Patel et al, 2003, Dominguez et al, 2007). The majority of women in these studies were aged $>50$ years and similar to those in our cohort. Concordance of CR is linked to the accuracy of selfreporting. Women have been found to be more accurate in reporting cancer history than men (Desai et al, 2001). Presence of established screening programmes also increases concordance. Self-reporting is also likely to be more accurate for carcinomas such as breast and bowel, with a definite histological diagnosis compared with lung cancer where presence of secondary lesions can lead to 
misinterpretation (Colditz et al, 1986). This is supported by the lower concordance with CR of self-reported lung cancer.

We further supplemented CR with HES data as Cancer Registries are using the hospital in-patient episode data as a registration source since 2009 (UKACR, 2011). This increased overall concordance by $1.6 \%$ with the highest increase $(5.2 \%)$ in lung cancer. Similar results have been reported by Moller et al (2011) and are in keeping with Swedish findings that a proportion of missing CR relates to cancer cases with no pathology reports where the diagnosis is recorded on the clinical letters, operation notes and imaging reports (Barlow et al, 2009).

The concordance varied by Cancer Registry from $86 \%$ (Thames Cancer Registry) to $96 \%$ (Wales Cancer Registry), possibly reflecting increased use of private health care in London. It has been previously reported that patients receiving private cancer care have missing registrations (Stotter et al, 2000) as CR in the UK (NCIN, 2012), unlike in Sweden, is not mandatory (Barlow et al, 2009). The mobile nature of the London population may have also contributed.

Strengths include the size (6000 women nested within a prospective cohort of 190000 ), complete 'flagging' through HSCIC because of availability of NHS number, use of additional information from HES and death certificates and follow-up for 5-years post censorship. We focussed on breast, bowel and lung cancer as participants were specifically asked about these cancers on two occasions (recruitment and followup). We chose cancer self-reporting as an independent measure against which to compare CR. The former is not a goldstandard and has limitations-some women may misreport a cancer or self-report in the absence of cancer (Fourkala et al, 2012). Another potential bias is that those who died shortly after their diagnosis may not have had the chance to complete the follow-up questionnaire. Small numbers make it difficult to draw definitive conclusions on lung cancers.

Knowledge of whether CR is complete and/or representative of all patients diagnosed with cancer is crucial to researchers as well as policymakers and clinicians who interpret and act on the research findings. Our study suggests high overall concordance of national CR with self-reported breast, bowel and lung cancer. Ongoing evaluation is important.

\section{ACKNOWLEDGEMENTS}

We are particularly grateful to the women throughout the UK who are participating in the trial and to the entire medical, nursing and administrative staff who work on UKCTOCS. The trial was core funded by the Medical Research Council, Cancer Research UK and the Department of Health with additional support from the Eve Appeal, Special Trustees of Bart's and the London, Special Trustees of UCLH and supported by researchers at the National Institute for Health Research, University College London, Hospitals Biomedical Research Centre. The funding source or the sponsor had no role in data collection, data analysis, data interpretation or writing of the report. The researchers are independent from the funders.

\section{CONFLICT OF INTEREST}

IJ has a consultancy arrangement with Becton Dickinson in the field of tumour markers and ovarian cancer, UM has a financial interest through UCL Business and Abcodia Ltd in the third party exploitation of clinical trials biobanks, which have been developed through the research at UCL. The remaining authors declare no conflict of interest.

\section{AUTHOR CONTRIBUTIONS}

UM and AGM were involved in study design and concept. UM, AGM and EOF did the literature search for this manuscript. UM and AGM drafted the manuscript. UM, AGM and MB prepared the tables. UM, AGM and $\mathrm{MB}$ did the statistical analysis. All authors critically revised the manuscript and approved the final version. UM is the guarantor.

\section{ETHICAL APPROVAL}

The study was approved by the UK North West Multicentre Research Ethics Committees (North West MREC 00/8/34) with site-specific approval from the local regional ethics committees and the Caldicott guardians (data controllers) of the primary care trusts. Approvals for the use of hospital episode statistics data were obtained as part of the standard hospitals episode statistics approval process.

\section{REFERENCES}

Barlow L, Westergren K, Holmberg L, Talback M (2009) The completeness of the Swedish Cancer Register: a sample survey for year 1998. Acta Oncol 48(1): 27-33.

Beral V, Peto R (2010) UK cancer survival statistics. BMJ 341: c4112. Colditz GA, Martin P, Stampfer MJ, Willett WC, Sampson L, Rosner B, Hennekens CH, Speizer FE (1986) Validation of questionnaire information on risk factors and disease outcomes in a prospective cohort study of women. Am J Epidemiol 123(5): 894-900.

Coleman MP, Forman D, Bryant H, Butler J, Rachet B, Maringe C, Nur U, Tracey E, Coory M, Hatcher J, McGahan CE, Turner D, Marrett L, Gjerstorff ML, Johannesen TB, Adolfsson J, Lambe M, Lawrence G, Meechan D, Morris EJ, Middleton R, Steward J, Richards MA, Group IMW (2011) Cancer survival in Australia, Canada, Denmark, Norway, Sweden, and the UK, 1995-2007 (the International Cancer Benchmarking Partnership): an analysis of population-based cancer registry data. Lancet 377(9760): 127-138.

Dejardin O, Rachet B, Morris E, Bouvier V, Jooste V, Haynes R, Coombes EG, Forman D, Jones AP, Bouvier AM, Launoy G (2013) Management of colorectal cancer explains differences in 1-year relative survival between France and England for patients diagnosed 1997-2004. Br J Cancer 108(4): 775-783.

Desai MM, Bruce ML, Desai RA, Druss BG (2001) Validity of self-reported cancer history: a comparison of health interview data and cancer registry records. Am J Epidemiol 153(3): 299-306.

Dominguez FJ, Lawrence C, Halpern EF, Drohan B, Grinstein G, Black DM, Smith BL, Gadd MA, Specht M, Kopans DB, Moore RH, Hughes SS, Roche CA, Hughes KS (2007) Accuracy of self-reported personal history of cancer in an outpatient breast center. J Genet Couns 16(3): 341-345.

Forbes LJ, Simon AE, Warburton F, Boniface D, Brain KE, Dessaix A, Donnelly C, Haynes K, Hvidberg L, Lagerlund M, Lockwood G, Tishelman C, Vedsted P, Vigmostad MN, Ramirez AJ, Wardle J and G International Cancer Benchmarking Partnership Module 2 Working (2013) Differences in cancer awareness and beliefs between Australia, Canada, Denmark, Norway, Sweden and the UK (the International Cancer Benchmarking Partnership): do they contribute to differences in cancer survival? Br J Cancer 108(2): 292-300.

Fourkala EO, Gentry-Maharaj A, Burnell M, Ryan A, Manchanda R, Dawnay A, Jacobs I, Widschwendter M, Menon U (2012) Histological confirmation of breast cancer registration and self-reporting in England and Wales: a cohort study within the UK Collaborative Trial of Ovarian Cancer Screening. Br J Cancer 106(12): 1910-1916.

Gathani T, Bull D, Green J, Reeves G, Beral V, Million Women C. Study Collaborators (2005) Breast cancer histological classification: agreement between the Office for National Statistics and the National Health Service Breast Screening Programme. Breast Cancer Res 7(6): R1090-R1096. 
Jensen AR, Overgaard J, Storm HH (2002) Validity of breast cancer in the Danish Cancer Registry. A study based on clinical records from one county in Denmark. Eur J Cancer Prev 11(4): 359-364.

Lang K, Magi M, Aareleid T (2003) Study of completeness of registration at the Estonian cancer registry. Eur J Cancer Prev 12(2): 153-156.

Maringe C, Walters S, Butler J, Coleman MP, Hacker N, Hanna L, Mosgaard BJ, Nordin A, Rosen B, Engholm G, Gjerstorff ML, Hatcher J, Johannesen TB, McGahan CE, Meechan D, Middleton R, Tracey E, Turner D, Richards MA, Rachet B, Group IMW (2012) Stage at diagnosis and ovarian cancer survival: evidence from the International Cancer Benchmarking Partnership. Gynecol Oncol 127(1): 75-82.

Menon U, Gentry-Maharaj A, Hallett R, Ryan A, Burnell M, Sharma A, Lewis S, Davies S, Philpott S, Lopes A, Godfrey K, Oram D, Herod J, Williamson K, Seif MW, Scott I, Mould T, Woolas R, Murdoch J, Dobbs S, Amso NN, Leeson S, Cruickshank D, McGuire A, Campbell S, Fallowfield L, Singh N, Dawnay A, Skates SJ, Parmar M, Jacobs I (2009) Sensitivity and specificity of multimodal and ultrasound screening for ovarian cancer, and stage distribution of detected cancers: results of the prevalence screen of the UK Collaborative Trial of Ovarian Cancer Screening (UKCTOCS). Lancet Oncol 10(4): 327-340.

Menon U, Gentry-Maharaj A, Ryan A, Sharma A, Burnell M, Hallett R, Lewis S, Lopez A, Godfrey K, Oram D, Herod J, Williamson K, Seif M, Scott I, Mould T, Woolas R, Murdoch J, Dobbs S, Amso N, Leeson S, Cruickshank D, McGuire A, Campbell S, Fallowfield L, Skates S, Parmar M, Jacobs I (2008) Recruitment to multicentre trials-lessons from UKCTOCS: descriptive study. BMJ 337: a2079.
Moller H, Richards S, Hanchett N, Riaz SP, Luchtenborg M, Holmberg L, Robinson D (2011) Completeness of case ascertainment and survival time error in English cancer registries: impact on 1-year survival estimates. Br J Cancer 105(1): 170-176.

NCIN (2012) 'Routes to Diagnosis - NCIN Data Briefing.' Retrieved 19 June 2013, Available at: http://www.ncin.org.uk/publications/data_briefings/ routes_to_diagnosis.

Parikh-Patel A, Allen M, Wright WE. C. California Teachers Study Steering (2003) Validation of self-reported cancers in the California Teachers Study. Am J Epidemiol 157(6): 539-545.

Parkin DM, Chen VW, Ferlasy J, Galceran J, Storm HH, Whelan SL (1994) Comparability and Quality Control in Cancer Registration. IARC Technical Report, No. 19. IARC.

Robinson D, Sankila R, Hakulinen T, Moller H (2007) Interpreting international comparisons of cancer survival: the effects of incomplete registration and the presence of death certificate only cases on survival estimates. Eur J Cancer 43(5): 909-913.

Stotter A, Bright N, Silcocks PB, Botha JL (2000) Effect of improved data collection on breast cancer incidence and survival: reconciliation of a registry with a clinical database. $B M J$ 321(7255): 214.

UKACR (2011) 'UKACR QUALITY AND PERFORMANCE INDICATORS 2011'. Retrieved 19 June 2013, Available at: http://www.ukacr.org/sites/ default/files/UKACR\%20report2011_final_0.pdf.

Woods LM, Coleman MP, Lawrence G, Rashbass J, Berrino F, Rachet B (2011) Evidence against the proposition that 'UK cancer survival statistics are misleading': simulation study with National Cancer Registry data. $B M J$ 342: d3399. 